\title{
Effect of the Timing of Defoliation on Fruit Growth and Abortion in a Parthenocarpic Cucumber
}

\author{
Patchareeya Boonkorkaew ${ }^{1}$, Yoko Mine ${ }^{2}$, Shoko HikosakA ${ }^{1}$, Akio TAZUKE ${ }^{3}$, \\ Wakanori AMAKI ${ }^{2}$ and Nobuo SUGIYAMA ${ }^{1}$ \\ ${ }^{1}$ Graduate School of Agricultural and Life Sciences, The University of Tokyo, \\ Bunkyo-ku, Tokyo 113-8657, Japan \\ ${ }^{2}$ Faculty of Agriculture, Tokyo University of Agriculture, Atsugi, Kanagawa 243-0034, Japan \\ ${ }^{3}$ College of Agriculture, Ibaraki University, Ami, Ibaraki 300-0393, Japan
}

(Received October 1, 2010; Accepted April 5, 2012)

\begin{abstract}
The effects of defoliation timing on fruit growth and abortion were monitored in gynoecious, parthenocarpic ' $\mathrm{NK} \times \mathrm{AN} 8$ ' cucumber. In control, non-defoliated plants, fruit attained marketable size at 14 days after anthesis (DAA), whereas some of the fruit from the plants (leaf-to-fruit ratio $=2$ ) defoliated at different time points were either stunted or aborted. Stunted and aborted fruit ceased to grow at about 7-8 DAA and at 4 DAA, respectively. When plants were defoliated at 4 DAA or earlier, more than $20 \%$ of the fruit aborted, whereas no fruit aborted when defoliated at 6 DAA or later. For fruits neither aborted nor stunted, the relative growth rate (RGR) of a fruit was almost the same for the period between 8 and 14 DAA irrespective of defoliation timing. In plants defoliated at 0 to 8 DAA, however, RGR decreased temporarily after defoliation. These results suggested that sufficient amount of photoassimilates should be continuously transported into fruits up to 4 DAA and 7-8 DAA in order to prevent fruit abortion and stunting, respectively.
\end{abstract}

Keywords : Cucumis sativus L., fruit abortion, leaf removal, leaf-to-fruit ratio

\section{INTRODUCTION}

Fruit growth in parthenocarpic cucumber is dependent on a sufficient supply of assimilates to the fruit (Marcelis, 1993). Competition for assimilates among the fruit (Hikosaka and Sugiyama, 2005) or the removal or shading of leaves (Kanahama and Saito, 1985) can lead to a reduced rate of fruit growth or to fruit abortion. Several authors have altered the leaf-to-fruit ratio (LFR) to manipulate assimilate availability and monitor the effects on fruit growth and abortion in cucumber (Kanahama and Saito, 1985), kiwifruit (Lai et al., 1989), chestnut (Famiani et al., 2000), and peach (Wu et al., 2005). In an experiment where LFR was manipulated two days after anthesis, Kanahama and Saito (1985) reported that fruit growth was delayed slightly with a decrease in LFRs from 5 and 3 to 2 . Furthermore, they clarified that fruit growth was delayed markedly at a LFR of 1 , and some fruits ceased to grow.

Hikosaka and Sugiyama $(2003,2005)$ reported that cucumber fruits at the middle nodes sometimes ceased to grow for more than 10 days and finally aborted, whereas fruits at the lower nodes did not cease or stopped growing for only one to two days. They assumed that the presence of fast growing fruits at the lower nodes restricted the assimilate supply to the newly-developed fruits at

Corresponding author: Yoko Mine, fax : +81-46-270-6290, e-mail : y3mine@nodai.ac.jp 


\section{P. BOONKORKAEW ET AL.}

the middle nodes, leading to fruit abortion at the middle nodes. Hikosaka and Sugiyama (2003) also found that the abortion rate of cucumber fruits at the middle nodes was affected by node position; plants tended to abort their fruits at the higher nodes, i.e, younger fruits. Therefore, it is possible that an incidence of fruit abortion is affected by the differences in fruit developmental phases. In the experiment of Kanahama and Saito (1985), they found that fruit stopped growing in two of four plants when LFR was adjusted to one at 2 days after anthesis (DAA), but they did not distinguish between the aborted fruits and stunted ones. Therefore, it remains unclear whether abortion rates were higher in fruits at early developmental phase under a limited assimilate supply. Here we examined the effect of defoliation at different time points on the subsequent fruit growth and fruit abortion and stunting in parthenocarpic cucumber plants.

\section{MATERIALS AND METHODS}

Cucumber seeds of the gynoecious, parthenocarpic 'NK $\times$ AN8' were sown on 3 Oct, 2006, and a number of the seedlings were transplanted 24 days after sowing (3-leaf stage). Two plants each were transplanted into a 20 -L plastic container filled with a growth medium containing a starter fertilizer $\left(0.4 \mathrm{~g} \mathrm{~N}, 0.9 \mathrm{~g} \mathrm{P}\right.$, and $\left.0.5 \mathrm{~g} \mathrm{~K} \mathrm{~kg}^{-1}\right)$. The plants were irrigated on a daily basis with water or a nutrient solution in $\left(\mathrm{mmol} \cdot \mathrm{L}^{-1}: \mathrm{NO}_{3}^{-}, 16 ; \mathrm{H}_{3} \mathrm{PO}_{4}^{-}, 4 ; \mathrm{Ca}^{2+}, 4 ; \mathrm{Mg}^{2+}, 2 ; \mathrm{K}^{+}, 8 ; \mathrm{NH}_{4}^{+}, 1.3\right)$. The temperature in the glasshouse was controlled at a range between $15^{\circ} \mathrm{C}$ and $25^{\circ} \mathrm{C}$ using ventilation during the day and heating at night. For both control and experimental groups, the lateral shoots and flowers below node 10 were removed, but the apical shoot remained unpinched. The experiment consisted of 2 treatments, namely, non-defoliation (control) and defoliation. In the defoliation treatment, 2 leaves at nodes 11 and 12, and 1 flower at node 11 were retained, while all other leaves and fruits were removed. The resulting LFR and total leaf area were 2 and 1,510 $( \pm 28) \mathrm{cm}^{2}$, respectively. Defoliation was carried out at $0,2,4,6$, and 8 DAA. The length and diameter of the ovary (fruit) at node 11 were monitored from 0 to 14 DAA for 10 plants in each treatment. The fruit fresh mass was estimated nondestructively based on the fruit length and diameter following Hikosaka and Sugiyama (2005). Fruit that turned brownish and withered was defined as aborted, while fruit that ceased to grow for more than 10 days but retained green color was defined as stunted. At the end of the experiment (14 DAA), the fruit was classified as normal, stunted, or aborted. The data of fruit fresh mass were presented as mean \pm standard error.

\section{RESULTS AND DISCUSSION}

Fruit stunting and abortion were observed when defoliation was performed at anthesis or a few days following it, with the effects dependent on the timing of defoliation. When defoliation was performed at $0,2,4,6$, and 8 days after anthesis (DAA), the sum of stunted and aborted fruit was $8,7,5,6$, and 0 fruit out of 10 , respectively (Fig. 1). Fruit abortion occurred when defoliation was performed at 4 DAA and earlier, while no stunted fruit was found when defoliation was performed at 8 DAA (Fig. 1). Stunted and aborted fruit each showed identical growth patterns irrespective of defoliation timing (Fig. 2); stunted fruit ceased to grow when the fresh mass reached approximately 2.5-3.0 $\mathrm{g}$ at 7-8 DAA, while aborted fruit ceased to grow when the fresh mass reached about 1.0$1.5 \mathrm{~g}$ at 4 DAA (Fig. 2). On the other hand, normal fruit, which was defined by continuous growth for 2 weeks after anthesis, also followed a similar growth pattern in all treatments. The slopes in the logarithm of fresh mass (RGR) for the period between 8 DAA and 14 DAA were almost the same irrespective of defoliation timing $(0.38,0.35,0.37,0.38$ and 0.36 when defoliated at $0,2,4$, 6 and 8 DAA, respectively), although RGR was slightly higher in control plants (0.46) (Fig. 2f). On the other hand, RGRs between 0 DAA and 8 DAA was decreased temporarily by defoliation in plants defoliated at 6 DAA and earlier, a low RGR being long-continued by earlier defoliation. 


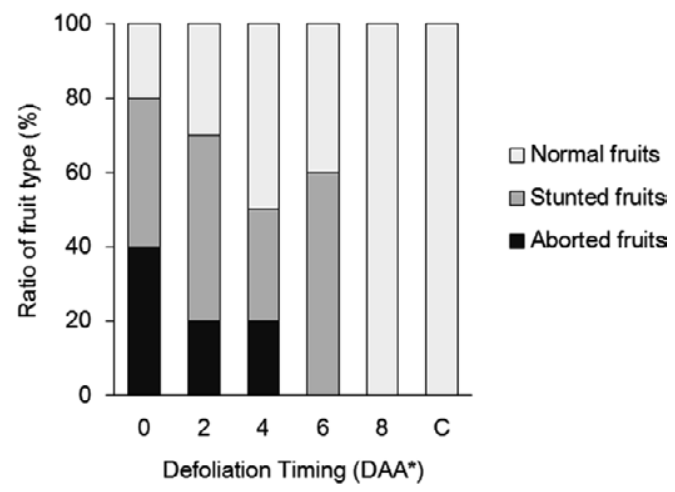

Fig. 1 The percentage of normal, stunted, and aborted fruit in control $(C)$ and defoliated plants $(n=10)$. DAA*; days after anthesis

As a result, a smaller fruit size was attained at 14 DAA in earlier defoliated plants (Fig. 2). In agreement with this result, Kanahama and Saito (1985) reported that fruits attained to a commercial size slowly when LFR was lower than two.

Bertin (1995) calculated competition of assimilates, i.e., the ability of fruits to attract assimilates, by the ratio between actual and potential fruit growth, assuming that potential fruit growth could be estimated when assimilate supply is higher than or equal to assimilate demand. In the present experiment, it is possible that potential growth was realized in control treatment because only one fruit was left on plants. As a result, we considered that a low ratio between actual and potential growth means an imbalance between assimilate supply and demand in a fruit; a temporary decrease in fruit RGR after defoliation at 6 DAA and earlier indicates an insufficient assimilate supply to fruits, leading to fruit stunting and abortion. Kanahama and Saito (1985) reported that fruit growth rates were more restricted when LFR was adjusted to two at 0 and 2 DAA than when adjusted at 4 and 6 DAA. Considering the relationship between defoliation timing and the occurrence of fruit abortion and stunting, it is probable that assimilate supply up to 4 DAA and 7-8 DAA was crucial for the occurrence of aborted fruit and stunted fruit, respectively. Boonkorkaew et al. (2008) demonstrated that fruit cell size began increasing rapidly at 4 DAA in non-pollinated fruits of parthenocarpic cucumber, while fruit cell number attained to a maximum at 4 DAA. Therefore, it is possible that a large amount of assimilates are required for the process of the cell division and the onset of cell enlargement as compared with the other developmental processes. Regarding susceptible period for abortion, Marcelis et al. (2004) stated that pepper flower/fruits from shortly before anthesis until about two weeks were susceptible to abortion in the experiment where plants were exposed to shading and heat stress at different developmental stage.

It is well known that the rate of abortion was negatively correlated with the growth rate of the earlier formed fruits which competed with later formed fruits for assimilates (Marcelis et al., 2004). However, Tazuke et al. (2008) stated that fruit abortion at the upper nodes was more related to the sum of RGR or number of fruits than the sum of growth rate of fruit at the lower nodes in parthenocarpic cucumber, suggesting higher ability of young fruit to attract assimilates. They assumed that fruit demand for assimilates is decreased after the initial growing period of fruits has been completed.

Kanahama and Saito (1985) stated that three leaves which corresponded to $1200 \mathrm{~cm}^{3}$ were necessary for the development of one fruit. In the defoliation treatment in the present study, leaf area was adjusted to about $1500 \mathrm{~cm}^{3}$, but fruit abortion and stunting occurred in some fruits. This suggested that factors other than LFR, e.g., leaf physiological activity and morphological properties, affect the minimum leaf area necessary for fruit development, leading to the different 

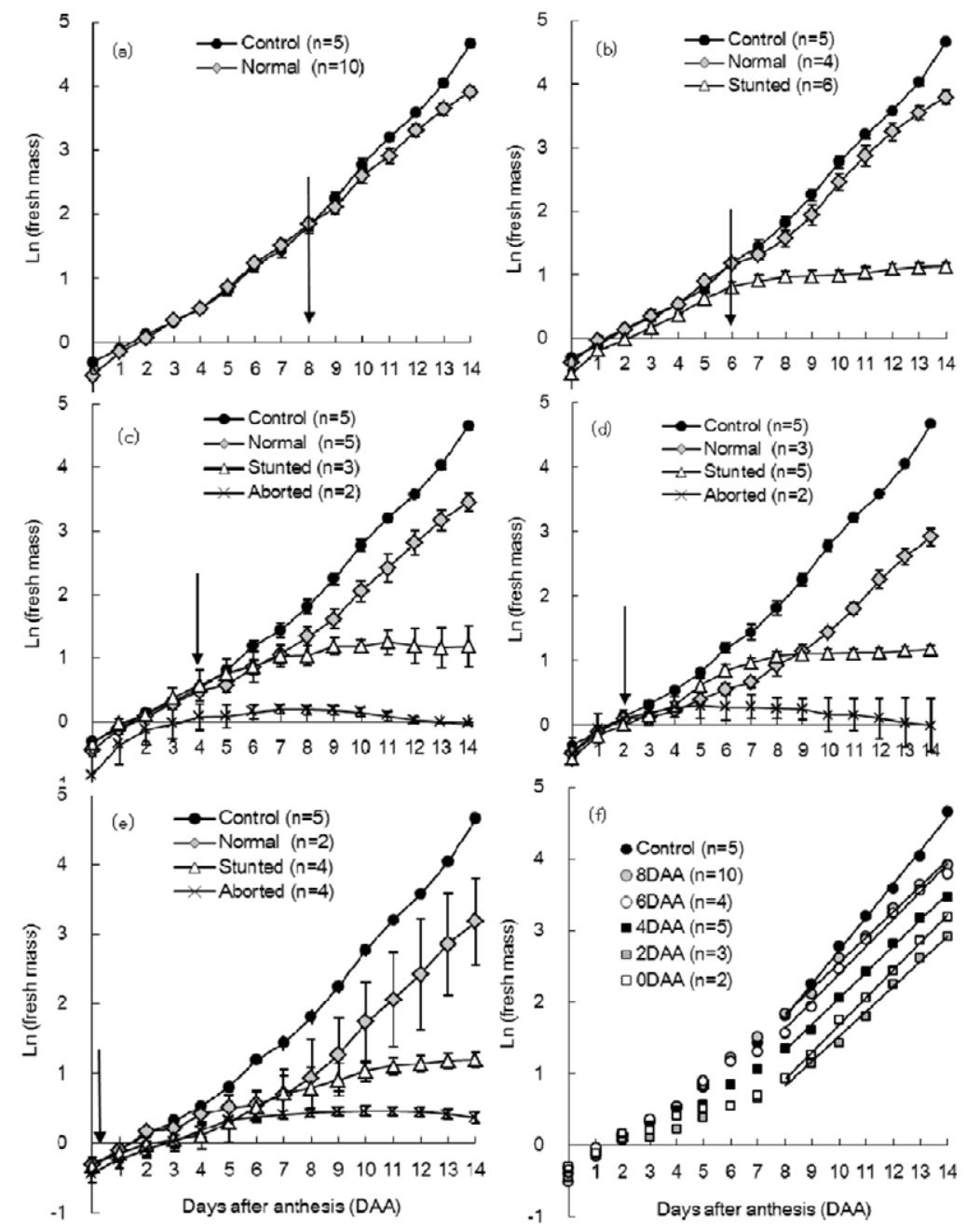

Fig. 2 Change in fruit fresh mass of cucumber plants defoliated at (a) 8 DAA, (b) 6 DAA, (c) 4 DAA, (d) 2 DAA, and (e) 0 DAA. Change in fresh mass of normal fruits in each treatment was redrawn in (f) with regression lines using data from 8 to 14 DAA. Arrows indicate the timing of defoliation. Changes in fruit fresh mass of control plants $(-$ were included in each graph for comparison. Fruit from defoliated plants were classified as normal $(\diamond)$, stunted $(\triangle)$, or aborted $(\times)$. The vertical bars represent the standard error. The numbers in parenthesis indicate the fruit number for each category.

responses to defoliation among plants.

In conclusion, we discovered that in parthenocarpic cucumber, 4 DAA and 7-8 DAA are the crucial periods for fruit abortion and stunting, respectively. This might cause the differences in the occurrence of fruit abortion due to node positions. It appears that unequal occurrence in fruit abortion and stunting among fruits in the middle nodes can be ascribed by the developmental differences of fruits. 


\section{REFERENCES}

Bertin, N. 1995. Competition for assimilates and fruit position affect fruit set in indeterminate greenhouse tomato. Ann. Bot. 75: 55-65.

Boonkorkaew, P., Hikosaka, S., Sugiyama, N. 2008. Effect of pollination on cell division, cell enlargement, and endogenous hormones in fruit development in a gynoecious cucumber. Sci. Hort. 116: 1-7.

Famiani, F., Proietti, P., Palliotti, A., Ferranti, F., Antognozzi, E. 2000. Effects of leaf to fruit ratios on fruit growth in chestnut. Sci. Hort. 85: 145-152.

Hikosaka, S., Sugiyama, N. 2003. Fruit growth patterns and abortion in multi-pistillate type cucumbers. J. Hort. Sci. Biotechnol. 78: 775-779.

Hikosaka, S., Sugiyama, N. 2005. Effect of fruit-load on growth patterns of fruit at the middle nodes of gynoecious-type cucumbers. J. Hort. Sci. Biotechnol. 80: 130-134.

Kanahama, K., Saito, T. 1985. Effects of the leaf number, fruit number and the shading of plants on the occurrence of fruit curvature in cucumber. J. Jpn. Soc. Hort. Sci. 54: 216-221.

Lai, R., Woolley, D. J., Lawes, G. S. 1989. Effect of leaf to fruit ratio on fruit growth of kiwifruit (Actinidia deliciosa). Sci. Hort. 39: 247-255.

Marcelis, L. F. M. 1993. Effect of assimilate supply on the growth of individual cucumber fruits. Physiol. Plant. 87: 313-320.

Marcelis, L. F. M., Heuvelink, E., Baan Hofman-Eijer, L. R., Den Bakker, J., Xue, L. B. $2004 . \quad$ Flower and fruit abortion in sweet pepper in relation to source and sink strength. J. Exp. Bot. 55: 2261-2268.

Tazuke, A., Boonkorkaew, P. Hikosaka, S., Sugiyama, N. 2008. Factors affecting fruit abortion in a gynoecious cucumber cultivar. J. Appl. Hort. 10: 15-19.

Wu, B. H., Ben Minoun, M., Genard, M., Lescourret, F., Besset, J., Bussi, C. 2005. Peach fruit growth in relation to the leaf-to-fruit ratio, early fruit size and fruit position. J. Hort. Sci. Biotechnol. 80: 340-345. 